\title{
STUDIES OF THE CAUSE OF PAIN IN GASTRIC AND DUODENAL ULCERS II.
}

\author{
PERISTALSIS AS THE DIRECT CAUSE OF PAIN IN GASTRIC \\ ULCERS WITH ACHYLIA AND IN DUODENAL ULCERS
}

\author{
LEO L. J. HARDT, M.D. \\ ROCHESTER, MINN.
}

For many years clinicians have been aware of the fact that not infrequently the symptoms of infection of the gallbladder and appendix and of achylia gastrica of unknown etiology may simulate those of typical gastric or duodenal ulcer. Since reflex pain may be indistinguishable from the true pain in ulcer, to what should this gastric pain, brought on by extragastric lesions, be attributed? Is there direct damage to the stomach and duodenum through this reflex mechanism?

In the consideration of the cause of gastric pain from gastric and duodenal ulcers or reflexly from an infected gallbladder, appendix, or achylia gastrica, two factors are of importance. On the one hand, is the question of acidity or hyperacidity and hypersecretion, and, on the other hand, variations in tonicity, intragastric tension, and peristalsis of the stomach and duodenum. Clinicians generally have been satisfied with the plausible explanation of hyperacidity and hypersecretion being the most likely cause of pain. As proof they administer alkalies which stop the pain, and quite logically they conclude that control of the pain and subsequent healing of the ulcer are mainly questions of neutralization. This view has been substantiated by Cannon ${ }^{1}$ in his classical work on the acid control of the pylorus. His theory does not explain the emptying of the stomach in gastric achylia, the rapid exit of water and egg albumin, nor the observations of Spencer, Meyer, Rehfuss and Hawk, ${ }^{2}$ that a 1 per cent. solution of sodium bicarbonate hastens the discharge from the normal human stomach.

The experimental work of Luckhardt, Phillips and Carlson ${ }^{3}$ indicates very conclusively that the pylorus opens for the ejection of chyme when it is reached by powerful advancing rings of contractions and when tonicity of the stomach musculature is greatly increased.

1. Camnon, W. B.: The Acid Control of the Pylorus, Am. J. Physiol. 20: 283, 1907.

2. Spencer, W. H. ; Meyer, G. P.; Rehfuss, M. E., and Hawk, P. B.: GastroIntestinal Studies. XII. Direct Evidence of Duodenal Regurgitation and Its Influence on the Chemistry and Function of the Normal Human Stomach, Am. J. Physiol. 39:459, 1915.

3. Luckhardt, A. B.; Phillips, H. T., and Carlson,' A. J.: Contributions to the Physiology of the Stomach, LI. The Control of the Pylorus, Am. J. Physiol. 1: 57, 1919. 
The gastric contents entering the duodenum are usually acid to phenolphthalein, but rarely show the presence of free acid to dimethylamidoazobenzaldehyd.

Carlson, ${ }^{4}$ Ginsburg, Tumpowsky and Hamburger ${ }^{5}$ and Hardt, ${ }^{6}$, working independently, have demonstrated, by means of kymographic records, various types of contractions and peristalsis of the stomach, which they concluded are the main factors in the causation of the pain of ulcer. New light was thrown on the etiology of pain, not only from gastric or duodenal 111cers, but also from achylia gastrica.

\section{INVESTIGATION}

Method.-The relation of gastric motility to pain was studied in twenty-five patients by the kymographic method. All patients were given a standard meal, consisting of two soft boiled eggs, two pieces of toast, two glasses of milk, and the juice of a grapefruit. From one to two hours later, two tubes were swallowed, a Rehfuss tube and a small rubber tube with a fine rubber balloon attached at one end and a chloroform manometer to the end which projected from the mouth. The balloon, held as closely as possible to the cardiac end of the stomach, was blown full of air; it was compressed according to the various types of contractions of the stomach, and thus air forced into the manometer caused the rider to record the variations in tonicity and the contractions on a slowly moving kymograph. These tracings were continued for from one to three hours, and at intervals of onehalf hour from 15 to 30 c.c. of stomach contents was aspirated to determine the presence or absence and percentage of free and total acids. The twenty-five patients were divided into two groups:

Group 1.-This group comprises twenty patients with duodenal ulcers, the majority of whom came to the clinic during a quiescent period in their trouble. The diagnosis was based on the clinical history and confirmed by roentgen-ray examination. All these patients were treated medically by the Sippy method at the completion of the kymographic record. None of the patients whose kymogram showed only Type I contractions (Fig. 1) experienced pain. All of these patients during the course of experiment revealed adequate free acids ranging from 20 to 90 (in terms of one-tenth normal hydrochloric acid). Six

4. Carlson, A. J.: Contributions to the Physiology of the Stomach, XLIV. The Origin of the Epigastric Pains in Cases of Gastric and Duodenal Ulcer, Am. J. Physiol. 45:81, 1918.

5. Ginsburg, H.; Tumpowsky, I., and Hamburger, W. W.: Contributions to the Physiology of the Stomach, XXXV. The Newer Interpretation of the Gastric Pain in Chronic Ulcer, J. A. M. A. 67:990 (Sept. 30) 1916.

6. Hardt, L. L. J.: Pain in Active Pathologic Processes in Stomach or Duodenum. Gastric and Duodenal Contractions as the Direct Cause, J. A. M. A. 70:837 (March 23) 1918. 
of the patients in whom contractions of Type III ( Fig. 2) or Type IV (Fig. 3) were recorded, experienced burning or gnawing pain similar to pain in ulcer, in practically every instance synchronous with the peristalsis, but as long as Type I contractions were recorded they were without pain.

The degree of acidity seemed to have little bearing on the pain. The acidity on the whole was lower at the time of the pain and active peristalsis than during the absence of pain and slight peristalsis.

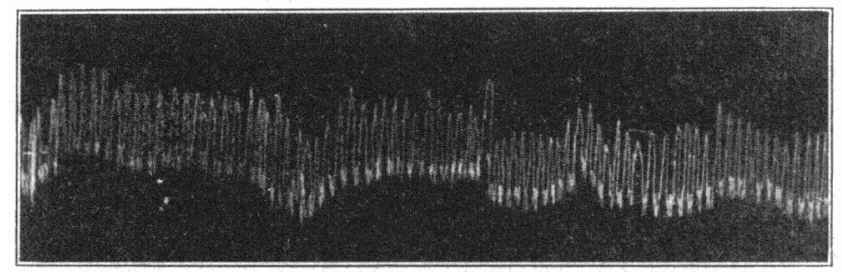

Fig. 1 (Case 147,732).--Type I contraction. Tonus variation or digestive peristalsis. without pain.

Group 2.-This group comprises five patients with achylia gastrica. Three patients were without pain and without any demonstrable pathologic condition, one patient harl gastric ulcer and one had pain without any demonstrable pathologic condition. The three patients without pain had no definite epigastric distress other than a little bloating or a burning sensation. Two of them revealed only Type I contractions during the course of the experiment; but the thitd had definite

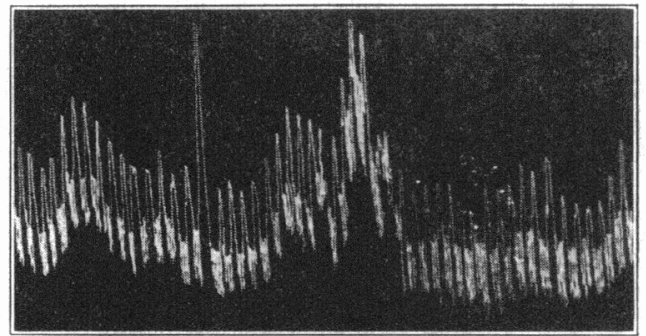

Fig. 2 (Case 1.351 .625$)$.--Type [1/ contraction. Beginning hunger peristalsis, with pain.

Type II (Fig. 4) and Type III peristalsis. These three patients cleariy show that normal tonus variations and peristalsis can be present in achylia gastrica. The patient with gastric ulcer (Case A147.7.32) had repeated gastric analyses which failed to reveal evidence of free acids. The typical cpigastric pain of a gastric ulcer continued, pain coming on from two to three hours after eating, with relief by food, water, alkalis, 
gastric lavage, and emesis. On several ocasions during a period of distress, acid-free contents were washed out of the stomach and the patient obtained prompt relief. Kymographic tracings begun two hours after a test meal showed tonts variations without pain (Fig. +) ; but gradually as the tonus variation were replaced by more active contractions of Type II and Type IV intermittent epigastric pain was complained of. which in almost every instance was synchronous with the peristalsis. The fifth patient (Case 1254.365 ) had pain typical of ulcer, differing somewhat in that it continued for long periods without remission, but

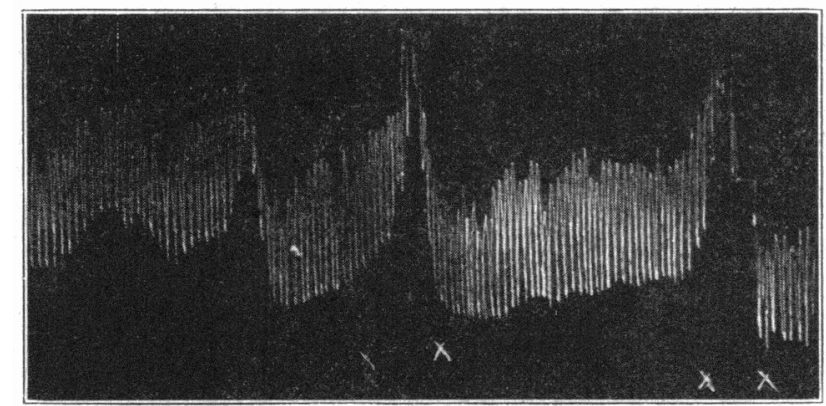

Fig. 3 (Case 1356,604 ),--Type IV contraction, Vigorous hunger peristalsis, which is coincident with gnawing or lorning pain.

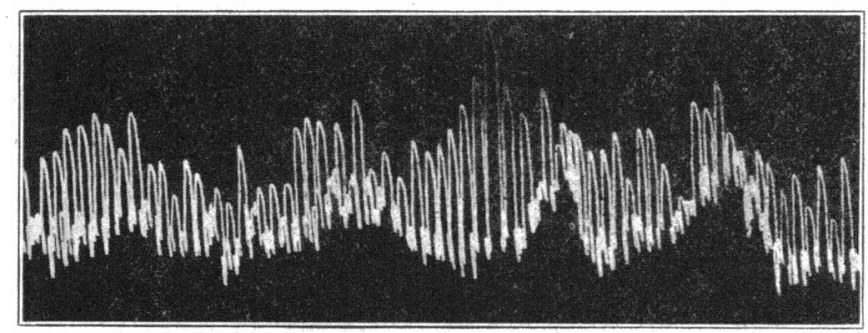

1.ig. 4 (Case 2254,355 ),-.Type 11 contraction. Faggeration of tonus variation which precedes the vigorous peristalsis: frequently associated with a moderate amount of pain.

no demonstrable pathologic condition. Several analyses of gastric contents failed to reveal any evidence of free acidity. It the time the patient experienced pain the kymograph recorded Type II (Fig. 4) and Type III (Fig. 2) contractions, the pain being absent during the periorl of slight tonus variations (Fig. 1).

\section{REPORT OF CASES}

C.13: 1 (A47.732),--llistory-S. A. M.. aged 49 years. lirst came to the Clinic, Dec. 11, 1915, complaining of epigastric pain three to four hours after meals. The attacks occurred in spells lasting from a few weeks to a month and remissions lasted from three to five month.s. Belching, drinking hot water, 
milk, or cream had usually given relief. For three months beginning August, 1915, he had vomited nearly every night between 1 and $3 \mathrm{a} . \mathrm{m}$.

Operation (Dec. 20, 1915). - This revealed a perforating duodenal ulcer extending into the pylorus, with adhesions to the head of the pancreas and with almost complete closure of the pylorus. Gastro-enterostomy and appendectomy were performed. Gastric analysis at this time revealed total acids 42 and free acids 30 , with laboratory findings pointing to pyloric obstruction. The patient was free from symptoms for three months following operation.

Course.-From 1916 until the patient's second admission to the Clinic, June 19,1921 , he had frequent attacks of epigastric pain two to three hours a fter meals, which were relieved by emesis, food and alkalies. Roentgen-ray examination revealed a gastric ulcer.

At operation, June 27, 1921, scar tissue was found on the duodenum, but no ulcer within. An ulcer $1.5 \mathrm{~cm}$. in diameter was located on the lesser curvature of the stomach, $3.75 \mathrm{~cm}$. above the pylorus. The gastro-enterostomy was found to be patent and functioning. The ulcer was excised and the diagnosis confirmed by microscopic examination.

Case 2 (A254,365).-History.-MI. T., aged 25 years, first came to the Clinic Dec. 26,1918 . He complained of epigastric distress of a burning character one hour after meals and at midnight. The pains were usually relieved by eating. In addition he complained of diarrhea which was closely associated with the epigastric distress. Gastric analysis failed to reveal any free acidity. Endameba histolytica was found in the stools. He was given emetin treatments for five days and sent home with advice as to treatment of diarrhea.

Dec. 26, 1919, the patient returned, still complaining of frequent attacks of burning pain in the epigastrium. The pain would be present for three or four days and then disappear for a week. The diarrbea had cleared up. He was given bromids three times daily after meals.

Dec. 27,1920 , the patient again returned with identical gastric complaints. The bromids had given relief for six months. This time he was given dilute hydrochloric acid, fifteen minutes after meals.

Aprii 19, 1921, the patient returned with epigastric pain which had not been relieved by the previous treatment with hydrochloric acid.

The stomach had been examined with the roentgen ray on each admission but no evidence of gastric or duodenal ulcer had been obtained. Repeated gastric analysis had failed to reveal any free acids.

At the last visit kymographic records were taken which showed that the pains were intermittent and coincident with the active peristalsis. Alkalies and tincture of belladonna gave relief.

\section{COMMENT}

The two groups of patients substantiate the theory of variations in tonicity and peristalsis as the main factor in the cause of gastric pain; the acidity is considered a secondary and in some cases not even a recessary finding, as in the two cases of achylia gastrica. That the motility and tonicity of the stomach is quite independent of the acidity is indicated by the cases of achylia in which all the normal contractions were obtained in the absence of acidity. Furthermore, emptying of the stomach was not interfered with, since in none of these cases were. there the slightest symptoms or signs of retention.

The quiescent period is probably the result of a diminution in the degree and extent of the inflammatory process, together with a decrease in the tonicity and contraction of the gastric and duodenal musculature. The administration of food, alkalies, water, emesis and gastric lavage 
temporarily produces this quiescent state, mainly through the inhibition of the peristalsis which is replaced by the nonpainful digestive peristalsis, described by Rogers and Hardt. ${ }^{7}$ The acid in all probability merely exaggerates to some extent the pain resulting from the more vigorous peristalsis and pyloroduodenal spasms.

The logical therapy in cases of gastric and duodenal ulcer should, it seems, tend primarily to inhibit peristalsis. About 85 per cent. of the patients treated surgically in the Mayo Clinic have been cured of the ulcer or satisfactorily improved. It might be assumed from these results that surgical procedures inhibit the vigorous peristalsis for a period long enough to promote healing of the ulcer, or at least a subsidence of the more acute inflammatory process. It is hoped that in the future this assumption can be demonstrated more conclusively by the kymographic method.

\section{CONCLUSIONS}

1. Gastric ulcer may be present in patients with achylia and may produce all the clinical symptoms characteristic of ulcer. The pain is primarily due to the peristalsis acting on an irritable focus. Ail the medical measures by which gastric acidity is neutralized and suppressed also inhibit the gastric peristalsis and thus relieve the pain.

2. Patients with gastric achylia in the absence of any demonstrable organic lesion may reveal the normal tonus variations and peristalsis.

3. Patients with uncomplicated duodenal ulcer do not experience pain during the period of digestive peristalsis, even in the presence of an adequate acidity. Active peristalsis of the "hunger type" (Types III and IV) is essential in the production of pain.

7. Rogers, F. T., and Hardt, L. L. J.: Contributions to the Physiology of the Stomach, XXVI. The Relation Between the Digestion Contractions of the Filled. and the Hunger Contractions of the "Empty" Stomach, Am. J. Physiol. 38:274, 1915 . 